\title{
Assessment on Credit Risk of Real Estate Based on Logistic Regression Model
}

\author{
Li Hongli ${ }^{1, a}$, Song Liwei ${ }^{2, b}$ \\ ${ }^{1}$ Chongqing Engineering Polytechnic College, Chongqing400037, China \\ ${ }^{2}$ Division of Planning and Finance, Chongqing University, Chongqing400030, China \\ a LHLGZ2008@163.com, ${ }^{\mathrm{b}}$ WSQYQH@163.com
}

Keywords: Real estate credit, Logistic regression model, Loan risk, Assessment

\begin{abstract}
Real estate industry, whose volatility will bring about the fluctuations of other related industries, is a basic industry highly associated with the national economy. With the development of real estate market in recent years, the non-rational growth of real estate credit of the commercial banks in China has increased the risk of real estate credit. The paper assesses the credit risk of listed real estate companies based on logistic regression model. The results show that on the whole the logistic regression model can predict accurately. The results of principal component analysis suggest that a company's capability to make profits is an important basis for the evaluation of credit risk. In addition, the assessment results of logistic regression model demonstrates that the prediction is asymmetric because the model makes a high predictive accuracy for credit non-default group, while a low predictive accuracy for credit default group.
\end{abstract}

\section{Introduction}

With the development of the real estate market in recent years, the non-rational growth of real estate credit of the commercial banks in China has increased the risk of real estate credit. Commercial banks loan a large amount of their credit money to real estate development enterprises, and the formation of corporate credit risk depends largely on the company's financial condition. Therefore, the measure of company credit risk can be transformed into a measure of company's financial problems. Listed property companies, as the backbone of the real estate industry, reflect the development of the whole industry. Thus, a study of the financial risk of a listed real estate development company has important practical significance for the prevention of bank credit risk. In this paper, 18 financial indicators of 37 listed real estate development companies are selected to establish evaluation index system. We try to use Logistic regression model to assess the real estate credit risk and analyze the results of the assessment based on the financial situation of the listed real estate companies.

\section{The construction of evaluation index system and the model sample selection}

\section{A. The construction of evaluation index system}

1) Principles for evaluation index design

The first step of real estate credit risk assessment is to establish an effective evaluation index system, which is the basis for credit risk assessment. Its design should be scientific and of systematic optimization, cost-effectiveness.

2) The construction of evaluation index system

There are many factors affecting the financial condition of a company. We can not, based on one indicator, judge whether a financial condition is good or not. Based on the existing literature, the characteristics of listed companies and the research needs, the quantitative index system of corporate credit rating is formulated by making a quantitative analysis about the indicators that can reflect the company's such abilities as solvency, profitability, operation and development etc. Therefore, this paper selects the evaluation indicators as shown in Table 1. 
TAB. 1 FINANCIAL INDICATORS TO BE SELECTED

\begin{tabular}{|c|c|c|c|c|c|}
\hline Categories & Financial Indicators & Number & Categories & $\begin{array}{l}\text { Financial } \\
\text { Indicators }\end{array}$ & Number \\
\hline \multirow{2}{*}{$\begin{array}{l}\text { Enterprise } \\
\text { scale } X_{1}\end{array}$} & Total assets & $\mathrm{X}_{11}$ & \multirow{7}{*}{$\begin{array}{l}\text { Profitability } \\
\text { assessment } \\
\mathrm{X}_{3}\end{array}$} & $\begin{array}{l}\text { Sales net profit } \\
\text { margin }\end{array}$ & $X_{31}$ \\
\hline & Equity & $\mathrm{X}_{12}$ & & $\begin{array}{l}\text { EBIT/Operating } \\
\text { ncome }\end{array}$ & $\mathrm{X}_{32}$ \\
\hline \multirow{3}{*}{$\begin{array}{l}\text { Solvency } \\
\text { evaluation } \mathrm{X}_{2}\end{array}$} & Current ratio & $\mathrm{X}_{21}$ & & EBIT/Total assets & $\mathrm{X}_{33}$ \\
\hline & Quick ratio & $\mathrm{X}_{22}$ & & Assets return ratio & $\mathrm{X}_{34}$ \\
\hline & Debt asset ratio & $\mathrm{X}_{23}$ & & $\begin{array}{l}\text { Total assets net } \\
\text { profit margin }\end{array}$ & $\mathrm{X}_{35}$ \\
\hline \multirow{3}{*}{$\begin{array}{l}\text { Operating } \\
\text { capacity } \\
\text { assessment } \\
\mathrm{X}_{4}\end{array}$} & Current assets turnover & $\mathrm{X}_{41}$ & & Current assets net & \\
\hline & Total assets turnover & $X_{42}$ & & & \\
\hline & & & \multirow{3}{*}{$\begin{array}{l}\text { Cash flow } \\
\text { assessment } \\
\mathrm{X}_{5}\end{array}$} & Cash flow ratio & $\mathrm{X}_{51}$ \\
\hline \multirow{2}{*}{$\begin{array}{l}\text { Development } \\
\text { capability } \\
\text { assessment } \\
\mathrm{X}_{6}\end{array}$} & $\begin{array}{l}\text { Fixed assets Growth } \\
\text { rate }\end{array}$ & $\mathrm{X}_{61}$ & & Debt coverage ratio & $\mathrm{X}_{52}$ \\
\hline & Total assets growth rate & $\mathrm{X}_{62}$ & & Operating index & $X_{53}$ \\
\hline
\end{tabular}

\section{B. Model Sample Selection}

To establish an effective prediction model, the model sample selection should include both the business failure group and the normal one. Business failure group is identified as ST business which refers to listed companies suffer losses for two consecutive years or their net asset of each share is lower than par value, which may result in bankruptcy. According to the qualitative theoretical analysis of credit risk, ST listed companies can be regarded as credit risk default companies and nonST listed companies as credit risk non-default group. This paper selects 37 listed companies of real estate development and management. In 2006, 9 companies are in the business failure group and 28 in the normal one. Using the financial data in 2004 to build model and to predict whether a financial crisis will happen two years later in the company, and comparing it with the actual situation in 2006, the validity of the model can be verified. To further verify the model's predictive ability, 11 companies happened financial crisis before 2007 (including 2007) are eliminated from the 37 sample companies. The financial data of the remaining 26 normal operation companies in 2007 are used to forecast the operating condition in 2009, and compare it with the actual situation in 2009. Sample companies' data are from the Guotai'an database.

\section{Real estate credit risk assessment based on the Logistic regression model}

\section{A. Model Design and Description}

In the process of measuring the credit risk, business success and failure is a dichotomous variable. As a dependent variable, company operation condition's probability value is between 0 and 1 . But under the condition that the linear model can not guarantee the various combinations of the independent variables, the value of the dependent variable is still between 0 and 1 . The solution to the problem is to make a logit conversion of the dependent variable, and it ranges between $-\infty$ and $+\infty$. In so doing, the Logistic regression method can be used to study the relation between business operation condition and its financial situation.

Suppose $X_{i}=\left(\chi_{1 i}, \chi_{2 i}, \ldots, \chi_{k i}\right)$ is the variable $\mathrm{k}$ to reflect the financial condition of the company $i$, $\alpha$ and $\beta$ are the parameters to be estimated, then, the bankruptcy probability of the company $i, p_{i}$ is:

$$
P\left(y_{i}=1 / x_{i}\right)=1 /\left[1+e^{-\left(\alpha+\beta x_{i}\right)}\right]
$$

The general form of Logistic regression model is: 


$$
\log \left[p_{i} /\left(1-p_{i}\right)\right]=\alpha+\sum_{k=1}^{K} \beta_{k} \chi_{k i}
$$

Use maximum likelihood estimation method to estimate the parameters $\alpha$ and $\beta$ in this equation, and then calculate the bankruptcy probability so as to judge the company's financial situation. When the $\mathrm{P}$ value is more than 0.5 , indicating that the probability of financial crisis is relatively large, we can determine that the company belongs to the financial crisis type; when the P value is less than 0.5 , indicating that the probability of normal finance is relatively large, so we can determine the company's finance is normal.

To determine the dependent variable, suppose the value yi in the default probability $\mathrm{p}\left(\mathrm{yi}=1 / \mathrm{x}_{\mathrm{i}}\right)$ is a random dichotomous variable, 1 for companies with abnormal operations and 0 for the normal operation companies

\section{B. Principal component analysis of the index system}

The basic idea of PCA is a statistical method to transform many interrelated value indicators into a few uncorrelated composite indicators by dimensionality reduction. That is to say, a small number of indicators are used to replace and reflect comprehensively more original information. The composite indicators are the main components of the original indicators.

One of the tasks for principal component analysis is to calculate the principal components: First, standardize the original indicators, and then calculate the correlation matrix between each indicator, the eigenvalue and eigenvector of the matrix, finally, list the eigenvalues in descending order, and calculate the corresponding principal component respectively. Generally, not all the principal components, but only the first few, are needed. Therefore, principal component analysis needs to determine the number of principal components. Here are two methods:

1) see the cumulative contribution rate: if the cumulative contribution rate of the first $\mathrm{k}$ principal components reaches certain value (generally $70 \%$ or more), then the first k principal components are retained.

2) see the eigenvalue: generally, principal components whose eigenvalue $\geqq 1$ are selected.

For both methods, the former gets more principal components while the latter gets less. Two methods are generally combined.

TAB. 2 TOTAL VARIANCE EXPLAINED

\begin{tabular}{|c|c|c|c|c|c|c|}
\hline \multirow{2}{*}{$\begin{array}{c}\text { Compone } \\
n t\end{array}$} & \multicolumn{3}{|c|}{ Initial Eigenvalues } & \multicolumn{2}{c|}{ Extraction Sums of Squared Loadings } \\
\cline { 2 - 7 } & Total & \% of Variance & Cumulative \% & Total & $\begin{array}{c}\text { \% of } \\
\text { Variance }\end{array}$ & Cumulative \% \\
\hline 1 & 6.952 & 38.624 & 38.624 & 6.952 & 38.624 & 38.624 \\
2 & 2.911 & 16.174 & 54.798 & 2.911 & 16.174 & 54.798 \\
\hline 3 & 2.084 & 11.575 & 66.373 & 2.084 & 11.575 & 66.373 \\
\hline 4 & 1.624 & 9.020 & 75.393 & 1.624 & 9.020 & 75.393 \\
\hline 5 & 1.572 & 8.731 & 84.125 & 1.572 & 8.731 & 84.125 \\
\hline 6 & 1.049 & 5.828 & 89.953 & 1.049 & 5.828 & 89.953 \\
\hline 7 & .596 & 3.308 & 93.261 & & & \\
\hline 8 & .412 & 2.287 & 95.548 & & & \\
\hline 9 & .377 & 2.097 & 97.645 & & & \\
\hline 10 & .168 & .934 & 98.579 & & & \\
\hline 11 & .103 & .574 & 99.153 & & & \\
\hline 12 & .062 & .344 & 99.497 & & & \\
\hline 13 & .050 & .275 & 99.772 & & & \\
\hline 14 & .032 & .176 & 99.948 & & & \\
\hline 15 & .007 & .038 & 99.986 & & & \\
\hline 16 & .002 & .009 & 99.994 & & & \\
\hline
\end{tabular}




\begin{tabular}{|l|c|c|c|c|c|c|}
\hline 17 & .001 & .006 & 100.000 & & & \\
18 & $2.343 \mathrm{E}-16$ & $1.302 \mathrm{E}-15$ & 100.000 & & & \\
\hline
\end{tabular}

Extraction Method: Principal Component Analysis.

TAB. 3 COMPONENT MATRIX

\begin{tabular}{|c|c|c|c|c|c|c|}
\hline & \multicolumn{7}{|c|}{ Component } \\
\cline { 2 - 7 } & 1 & 2 & 3 & 4 & 5 & 6 \\
\hline Current ratio & .521 & .264 & -.505 & .271 & -.314 & -.267 \\
\hline Quick ratio & .274 & .696 & -.508 & .316 & -.079 & -.047 \\
\hline Debt asset ratio & -.644 & -.433 & .330 & -.292 & .013 & .263 \\
\hline Sales net profit margin & .912 & -.059 & .213 & .128 & -.031 & -.004 \\
\hline EBIT/ Operating income & .920 & -.092 & .202 & .050 & .007 & -.047 \\
\hline EBIT/ Total assets & .931 & -.086 & .288 & -.033 & -.106 & .001 \\
\hline Assets return ratio & .931 & -.086 & .288 & -.033 & -.106 & .001 \\
\hline Total assets net profit margin & .941 & -.087 & .247 & -.009 & -.122 & .015 \\
\hline Current assets net profit margin & .919 & -.053 & .256 & -.012 & -.127 & .004 \\
\hline Current assets turnover & -.434 & .362 & .483 & .586 & .097 & .187 \\
\hline Total assets turnover & -.270 & .204 & .600 & .612 & -.038 & .212 \\
Cash flow ratio & .154 & .867 & .122 & -.307 & .141 & .173 \\
\hline Debt coverage ratio & .181 & .889 & .078 & -.300 & .103 & .159 \\
\hline Operating index & -.034 & -.423 & -.238 & .625 & .142 & -.086 \\
\hline Fixed assets Growth rate & .169 & .014 & -.435 & .169 & -.325 & .725 \\
\hline Total assets growth rate & .453 & -.440 & -.373 & -.112 & -.168 & .442 \\
\hline Zscore: Asset & .448 & -.209 & -.116 & .030 & .802 & .197 \\
Zscore: Equity & .544 & .032 & -.265 & .095 & .758 & .033 \\
\hline
\end{tabular}

Extraction Method: Principal Component Analysis.

a. 6 components extracted.

After using SPSS to do principal component analysis for the 18 indicators, from Table 2, Total variance explained, and Table 3, Component matrix, we can draw the following conclusions:

6 eigenvalues are bigger than 1, the cumulative contribution rate reaches $89.953 \%$, so 6 principal components are determined. The contribution rate of the first principal component is $38.624 \%$, mainly due to the impact of corporate profitability, followed by long-term solvency of the enterprise; the contribution rate of the second principal component is $16.174 \%$, mainly affected by cash flow capacity; the contribution rate of the third principal component is $11.575 \%$, mainly due to the impact of short-term solvency of the enterprise; the contribution rate of the fourth principal component is $9.02 \%$, mainly affected by company's operation capacity; the contribution rate of the fifth principal component is $8.731 \%$, mainly affected by the company scale; the contribution rate of the sixth principal component is $5.828 \%$, mainly due to the impact of company's development capacity.

According to the results of the above principal component analysis, preliminary judgments are made that before giving loans to real estate development company, commercial banks will take the enterprise's profitability, operation, cash flow, solvency, scale and development capacity into account comprehensively, and pay enough attention to the corresponding financial indicators. The priority order of various financial indicators is: profitability $>$ long-term solvency $>$ cash flow capacity $>$ short-term solvency $>$ operating capacity $>$ scale $>$ development capacity. Needless to say, enterprise profitability is an important factor affecting credit risk; then the higher the enterprise's long-term solvency and the debt asset ratio are, the greater the risk of future loan default is; company's cash flow ability reflects, from another angle, the level and quality of the listed company's profitability, indirectly affecting its solvency; in addition, enterprise's operation capability plays a significant role in affecting the repayment risk, the stronger the operation capacity is, meaning that the better the asset liquidity is, the stronger the short-term solvency is; finally, 
company's level, scale and future development capacity is also an important factor affecting credit risk. Therefore, the conclusions from the data processing are in line with objective reality, having certain reference value for banks to assess mortgage risk.

TAB. 4 COMPONENT SCORE COEFFICIENT MATRIX

\begin{tabular}{|c|c|c|c|c|c|c|}
\hline & \multicolumn{7}{|c|}{ Component } \\
\cline { 2 - 7 } & 1 & 2 & 3 & 4 & 5 & 6 \\
\hline Current ratio & .075 & .091 & -.242 & .167 & -.200 & -.254 \\
\hline Quick ratio & .039 & .239 & -.244 & .194 & -.050 & -.045 \\
\hline Debt asset ratio & -.093 & -.149 & .159 & -.180 & .008 & .251 \\
\hline Sales net profit margin & .131 & -.020 & .102 & .079 & -.020 & -.004 \\
\hline EBIT/ Operating income & .132 & -.031 & .097 & .031 & .004 & -.044 \\
\hline EBIT/ Total assets & .134 & -.030 & .138 & -.020 & -.067 & .001 \\
\hline Assets return ratio & .134 & -.030 & .138 & -.020 & -.067 & .001 \\
\hline Total assets net profit margin & .135 & -.030 & .118 & -.006 & -.078 & .015 \\
\hline Current assets net profit margin & .132 & -.018 & .123 & -.007 & -.081 & .003 \\
\hline Current assets turnover & -.062 & .124 & .232 & .361 & .062 & .178 \\
\hline Total assets turnover & -.039 & .070 & .288 & .377 & -.024 & .202 \\
\hline Cash flow ratio & .022 & .298 & .059 & -.189 & .090 & .165 \\
\hline Debt coverage ratio & .026 & .305 & .037 & -.185 & .066 & .152 \\
\hline Operating index & -.005 & -.145 & -.114 & .385 & .090 & -.082 \\
\hline Fixed assets Growth rate & .024 & .005 & -.209 & .104 & -.207 & .691 \\
\hline Total assets growth rate & .065 & -.151 & -.179 & -.069 & -.107 & .421 \\
Zscore: Asset & .064 & -.072 & -.056 & .018 & .510 & .188 \\
\hline Zscore: Equity & .078 & .011 & -.127 & .059 & .482 & .032 \\
\hline
\end{tabular}

Extraction Method: Principal Component Analysis.

Component Scores.

From Table 4 Component score coefficient matrix, all the principal components can be expressed as linear combinations of the variables. The formula is as follows:

$$
\begin{aligned}
& F_{i}=\alpha_{1 i} * s t d \chi_{21}+\alpha_{2 i} * s t d \chi_{22}+\alpha_{3 i} * s t d \chi_{23}+\alpha_{4 i} * s t d \chi_{31}+\alpha_{5 i} * s t d \chi_{32}+\alpha_{6 i} * s t d \chi_{33}+ \\
& \alpha_{7 i} * s t d \chi_{34}+\alpha_{8 i} * s t d \chi_{35}+\alpha_{9 i} * s t d \chi_{36}+\alpha_{10 i} * s t d \chi_{41}+\alpha_{11 i} * s t d \chi_{42}+\alpha_{12 i} * s t d \chi_{51}+ \\
& \alpha_{13 i} * s t d \chi_{52}+\alpha_{14 i} * s t d \chi_{53}+\alpha_{15 i} * s t d \chi_{61}+\alpha_{16 i} * s t d \chi_{62}+\alpha_{17 i} * s t d Z\left(\chi_{11}\right)+\alpha_{18 i} * s t d Z\left(\chi_{12}\right)
\end{aligned}
$$

Of which: $i=1,2,3,4,5,6$; std $\chi$ means standard indicator variable, $\operatorname{std} \chi=(\chi-\mu) / \sigma$

\section{Model estimation and prediction analysis}

The equations are an exception to the prescribed spe Based on the logistic regression method, a backward stepwise method is used to make a regression of the 6 principal components from principal component analysis, the regression results are as follows:

1) Hosmer and lemeshow test

The null hypothesis of Hosmer and Lemeshow test is: the model fits the data well. From the significance test of the final model, Sig $=0.844>0.5$, the null hypothesis can not be denied, meaning that the model fits the data well. Based on the forecast probability of the target variables, the results are divided into nine groups by the Contingency Table for Hosmer and Lemeshow Test. In Table 6, the observed values and expected values in each row are roughly the same, so the model's fitting results are good.

TAB. 5 HOSMER AND LEMESHOW TEST

\begin{tabular}{|c|c|c|c|}
\hline Step & Chi-square & Df & Siq. \\
\hline 1 & .795 & 7 & .997 \\
6 & 3.414 & 7 & .844 \\
\hline
\end{tabular}


TAB. 6 CONTINGENCY TABLE FOR HOSMER AND LEMESHOW TEST

\begin{tabular}{|c|c|c|c|c|c|c|}
\multicolumn{2}{c|}{} & \multicolumn{2}{c|}{ 06 if ST $=06$ not ST } & \multicolumn{2}{c|}{ 06 if ST=06 is ST } & \multirow{2}{*}{ Total } \\
\cline { 3 - 7 } \multicolumn{2}{c|}{} & Observed & Expected & Observed & Expected & \\
\hline \multirow{5}{*}{ Step 6 } & 1 & 4 & 3.984 & 0 & .016 & 4 \\
\cline { 2 - 7 } & 2 & 4 & 3.963 & 0 & .037 & 4 \\
& 3 & 4 & 3.941 & 0 & .059 & 4 \\
\cline { 2 - 7 } & 4 & 4 & 3.899 & 0 & .101 & 4 \\
& 5 & 4 & 3.818 & 0 & .182 & 4 \\
\cline { 2 - 7 } & 7 & 3 & 3.721 & 1 & .279 & 4 \\
& 8 & 3 & 2.991 & 1 & 1.009 & 4 \\
\cline { 2 - 7 } & 9 & 1 & 1.272 & 3 & 2.728 & 4 \\
\hline
\end{tabular}

2) Model Construction

Table 7 shows that the significance of the variable $F_{1}$ in the equation is less than $0.05, F_{4}$ 's significance is more than 0.05 , indicating that $F_{1}$ 's contribution to the equation is significant while $\mathrm{F}_{4}$ 's contribution to the equation is not very significant. In Table 8, the significances of the variables not in the equation are far more than 0.05 , so that the contribution of each independent variable in the final regression equation to the equation is significant. The coefficients in Exp (B) column demonstrate that if any unit in $\mathrm{F}_{4}$ changes, then the ratio of event occurrence (Odds) 2.904 is bigger than $\mathrm{F}_{1}$ 's influence rate. The bivariate Logistic regression model from the coefficients in column $\mathrm{B}$ is as follows:

$\mathrm{p}=1 /\left(1+\mathrm{e}^{-\mathrm{z}}\right)$

Of which, $\quad Z=-2.178-2.775^{F_{1}}+1.066^{F_{4}}$

Put the factor coefficients of Principal component analysis in Table 4 into the above equation, the following can be obtained:

$$
\begin{aligned}
& Z=-2.178-0.16^{\text {std } \chi_{11}}-0.15^{\text {std }} \chi_{12}-0.03{ }^{s t d} \chi_{21}+0.1{ }^{s t d} \chi_{22}+0.07^{\text {std } \chi_{23}}-0.28^{\text {std }} \chi_{31}-0.33^{\text {std }} \chi_{32}- \\
& 0.39{ }^{s t d} \chi_{33}-0.39{ }^{\text {std } \chi_{34}}-0.38{ }^{\text {std } \chi_{35}}-0.37{ }^{\text {std } \chi_{36}}+0.56 \text { std } \chi_{41}+0.51{ }^{\text {std } \chi_{42}}-0.26 \text { std } \chi_{51} \quad \\
& 0.27^{\text {std } \chi_{52}}+0.42^{\text {std } \chi_{53}}+0.04^{\text {std } \chi_{61}-0.25^{\text {std }} \chi_{62}}
\end{aligned}
$$

Revert the standard independent variables to the original independent variables, ${ }^{t t d} \chi=(\chi-\mu) / \sigma$, the linear equation between dependent variable $Z$ and the original independent variable is as follows:

$$
\begin{aligned}
& z=-3.776-8.011 \mathrm{E}^{-11} \chi_{11}-1.359 \mathrm{E}^{-10} \chi_{12}-0.027 \chi_{21}+0.148 \chi_{22}+0.373 \chi_{23}-0.916 \chi_{31}-1.118 \chi_{32}- \\
& 4.402 \chi_{33}-4.402 \chi_{34}-4.123 \chi_{35}-2.145 \chi_{36}+1.854 \chi_{41}+2.417 \chi_{42}-0.553 \chi_{51}- \\
& 0.593 \chi_{52}+0.026 \chi_{53}+0.046 \chi_{61}-0.678 \chi_{62}
\end{aligned}
$$

It can be seen from the above equation that enterprise's assets scale has the biggest impact on credit risk. In general, the larger the enterprise scale is, the stronger its ability to bear risk is and the lower the likelihood of default in the future is; secondly, the profitability of enterprise can also greatly influence credit risk. Be specific to the financial indicator, the impact of such indicators as EBIT/ total assets, assets return ratio, total assets net profit margin and current assets net profit

\begin{tabular}{|c|c|c|c|c|c|c|c|}
\hline & & $B$ & S.E. & Wald & $d f$ & Siq. & $\operatorname{Exp}(B)$ \\
\hline \multirow{3}{*}{ Step $6^{\mathrm{a}}$} & FAC1 1 & -2.775 & .914 & 9.228 & 1 & .002 & .062 \\
\hline & FAC4 1 & 1.066 & .670 & 2.531 & 1 & .112 & 2.904 \\
\hline & Constant & -2.178 & .840 & 6.720 & 1 & .010 & .113 \\
\hline
\end{tabular}
margin etc. on the financial risk of enterprise is next only to its assets scale; in addition, total assets turnover and current assets turnover have some big impact on the risk probability too. In other words, enterprise's operating ability has a big influence on its credit risk probability. Empirical findings are basically consistent with the actual.

TAB.7 VARIABLES IN THE EQUATION 
a. Variable (s) entered on step 1: FAC1_1, FAC2_1, FAC3_1, FAC4_1, FAC5_1, FAC6_1.

TAB.8 VARIABLES NOT IN THE EQUATION

\begin{tabular}{|c|c|c|c|c|c|}
\hline & & Score & $d f$ & Siq. \\
\hline \multirow{4}{*}{ Step 6 } & & & .054 & 1 & .817 \\
& \multirow{4}{*}{ Variables } & FAC2 1 & 1.281 & 1 & .258 \\
\cline { 3 - 6 } & & FAC3 1 & .424 & 1 & .515 \\
\cline { 3 - 6 } & & FAC5 1 & 1.493 & 1 & .222 \\
\cline { 2 - 6 } & & FAC6 1 & 2.878 & 4 & .578 \\
\hline
\end{tabular}

a. Variable (s) removed on step 5: FAC6 1 .

3) Prediction results evaluation

Empirical study demonstrates that Logistic regression model can accurately predict enterprise's credit default. Table 9 shows the classifications of Logistic regression model which indicate that whether the 37 listed property companies suffered ST treatment in 2006 or not. Sample estimation error rate by the model for the first classification is $7.1 \%$ while the second is $22.2 \%$. The overall prediction accuracy rate is $89.2 \%$. Figure 1 is a schematic diagram of the classification results, showing that two normal enterprises are mistaken as default while two default enterprises are misjudged as non-default.

TAB.9 FORECAST CLASSIFICATION TABLE

\begin{tabular}{|c|c|c|c|c|c|}
\hline & \multirow{2}{*}{\multicolumn{2}{|c|}{ Observed }} & \multicolumn{3}{|c|}{ Predicted } \\
\hline & & & & & Percentage \\
\hline \multirow[b]{2}{*}{ Step 6} & 06 if ST & 06 not ST & $\begin{array}{c}06 \text { not ST } \\
26\end{array}$ & $\begin{array}{c}06 \text { is } \mathrm{ST} \\
2\end{array}$ & $\begin{array}{c}\text { Correct } \\
92.9\end{array}$ \\
\hline & Overa & $\begin{array}{l}06 \text { is ST } \\
\text { entage }\end{array}$ & 2 & 7 & $\begin{array}{l}77.8 \\
89.2\end{array}$ \\
\hline
\end{tabular}

a. The cut value is .500

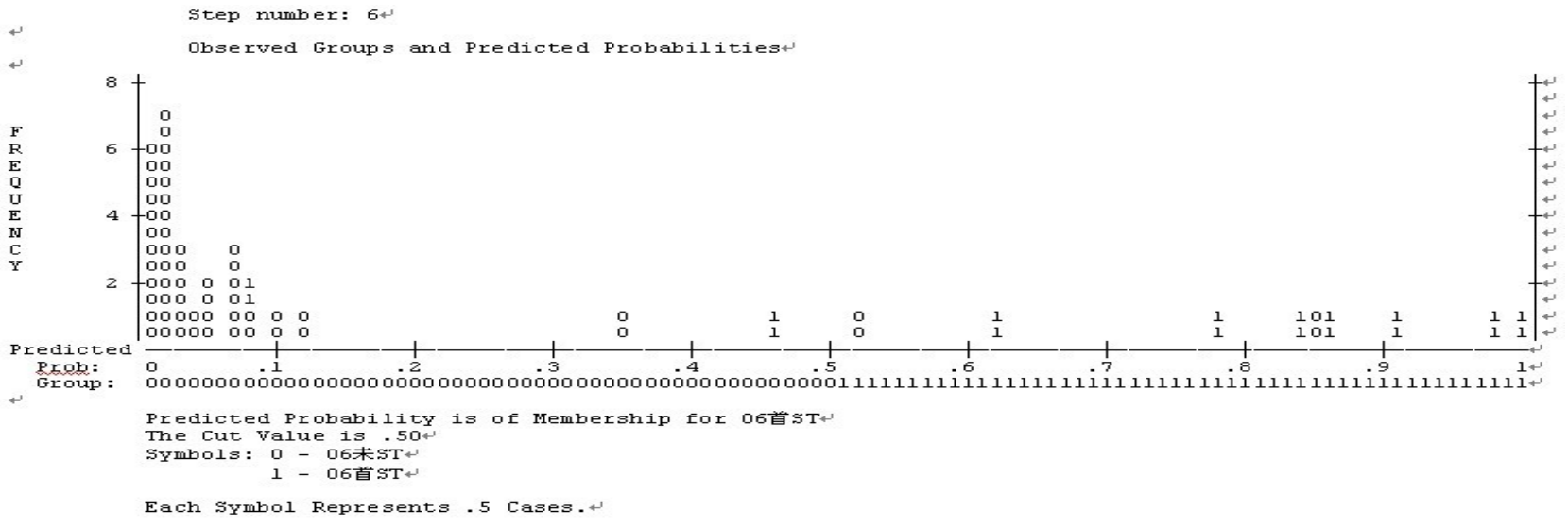

Figure.1 Logistic regression classification diagram

To find out which four companies have been misjudged, the enterprise's default probability can be calculated based on the financial indicators of the listed enterprise. Table 10 shows the comparison between the default probability predicted by the financial indicators of 37 sample enterprises in 2004 and the actual occurrences two years later, i.e. 2006. We can see, the predicted default probability of enterprises whose codes are 000007 and 000616 is bigger than 0.5 . It can be inferred that a financial crisis will occur in 2006 , so that credit default will occur too. But the fact is that in 2006 the two companies didn't suffer ST treatment, no credit default happened. Therefore, the prediction is wrong. In fact, enterprise 000007 didn't suffer ST treatment in 2006, but in 2007 suffered ST treatment, indicating that the occurrence postponed for one year, so it may not be regarded as a forecast error; the predicted default probability of enterprises whose codes are 000540 and 600225 is less than 0.5 . It can be inferred that a financial crisis will not occur in 2006, which 
means no default will happen. However, this is just the opposite of the actual situation in 2006, the two suffered ST treatment, thus a forecast error.

TAB.10 2006 COMPARISON BETWEEN THE ACTUAL AND PREDICTED PROBABILITY

\begin{tabular}{|c|l|l|l|l|l|l|l|l|}
\hline Code & $\begin{array}{c}\text { Predicted } \\
\text { probability }\end{array}$ & $\begin{array}{c}\text { The } \\
\text { actual }\end{array}$ & Code & $\begin{array}{c}\text { Predicted } \\
\text { probability }\end{array}$ & $\begin{array}{c}\text { The } \\
\text { actual }\end{array}$ & Code & $\begin{array}{c}\text { Predicted } \\
\text { probability }\end{array}$ & $\begin{array}{c}\text { The } \\
\text { actual }\end{array}$ \\
\hline 000006 & 0.111 & 0 & 000667 & 0.019 & 0 & 600634 & 0.002 & 0 \\
\hline 000007 & 0.848 & 0 & 000918 & 0.978 & 1 & 600638 & 0.007 & 0 \\
\hline 000014 & 0.069 & 0 & 000979 & 0.999 & 1 & 600639 & 0.005 & 0 \\
\hline 000031 & 0.010 & 0 & 600052 & 0.015 & 0 & 600657 & 0.772 & 1 \\
\hline 000042 & 0.349 & 0 & 600173 & 0.610 & 1 & 600663 & 0.002 & 0 \\
\hline 000402 & 0.008 & 0 & 600225 & 0.076 & 1 & 600665 & 0.041 & 0 \\
\hline 000502 & 0.063 & 0 & 600246 & 0.094 & 0 & 600675 & 0.013 & 0 \\
\hline 000511 & 0.027 & 0 & 600325 & 0.008 & 0 & 600684 & 0.034 & 0 \\
\hline 000540 & 0.455 & 1 & 600376 & 0.062 & 0 & 600732 & 0.026 & 0 \\
\hline 000558 & 0.072 & 0 & 600393 & 0.013 & 0 & 600748 & 0.011 & 0 \\
\hline 000573 & 0.045 & 0 & 600533 & 0.019 & 0 & 600773 & 0.854 & 1 \\
\hline 000608 & 0.029 & 0 & 600614 & 0.831 & 1 & 600890 & 0.907 & 1 \\
\hline 000616 & 0.512 & 0 & & & & & & \\
\hline
\end{tabular}

If we remove the enterprises which happened financial crisis and suffered ST treatment before 2007 (including 2007) from the samples, and verify the model's predictive ability, using the financial data of the normal operation enterprises in 2007, now, 26 out of the original 37 sample companies remain, then predict the probability of financial crisis in 2009 based on Equation (4) and Equation(6), and compare it to the situation actually occurred in 2009, we can find that the model prediction is entirely consistent with the actual situation, as shown in Table 11. This further proves the applicability of the constructed model.

TAB. 112009 COMPARISON BETWEEN THE ACTUAL AND PREDICTED PROBABILITY

\begin{tabular}{|r|c|c|c|c|c|c|c|c|}
\hline \multicolumn{1}{|c|}{$\begin{array}{c}\text { Co } \\
\text { de }\end{array}$} & $\begin{array}{l}\text { Predicted } \\
\text { probability }\end{array}$ & $\begin{array}{l}\text { The } \\
\text { actual }\end{array}$ & Code & $\begin{array}{l}\text { Predicted } \\
\text { probability }\end{array}$ & $\begin{array}{l}\text { The } \\
\text { actual }\end{array}$ & Code & $\begin{array}{l}\text { Predicted } \\
\text { probability }\end{array}$ & $\begin{array}{l}\text { The } \\
\text { actual }\end{array}$ \\
\hline 000 & 0.006 & 0 & 00060 & 0.013 & 0 & 60063 & 0.006 & 0 \\
\hline 000 & 0.032 & 0 & 00061 & 0.014 & 0 & 60063 & 0.007 & 0 \\
\hline 000 & 0.001 & 0 & 00066 & 0.005 & 0 & 60066 & 0.001 & 0 \\
\hline 000 & 0.151 & 0 & 60024 & 0.007 & 0 & 60066 & 0.020 & 0 \\
\hline 000 & 0.005 & 0 & 60032 & 0.006 & 0 & 60067 & 0.002 & 0 \\
\hline 000 & 0.125 & 0 & 60037 & 0.007 & 0 & 60068 & 0.031 & 0 \\
\hline 000 & 0.013 & 0 & 60039 & 0.068 & 0 & 60073 & 0.044 & 0 \\
\hline 000 & 0.050 & 0 & 60053 & 0.016 & 0 & 60074 & 0.018 & 0 \\
\hline 000 & 0.029 & 0 & 60063 & 0.000 & 0 & & & \\
\hline
\end{tabular}

\section{Conclusion}

This paper takes 37 listed real estate development companies as samples, and tries to use Logistic regression model to analyze and assess the credit risk of listed real estate companies. Comparing with the studies already done at home and abroad, it has made some useful attempts in terms of assessment indicators, model sample data, analysis methods and model checking. The results of the study show that:

1) Logistic regression model's overall predicted results are relatively good, and its predictive accuracy reaches $89.2 \%$;

2) Logistic regression model demonstrates that enterprise's assets scale and profitability are the major factors used to estimate risk, and the method shows that enterprise profitability is an important aspect affecting the credit risk;

3) The results of the model prediction are asymmetric. The forecast accuracy of Logistic regression model for credit non-default group is higher, while for credit default group is lower. On the one hand, it reflects truly the fact that it's rare to see that enterprises which operates well make false accounting and exaggerate profits, while the moral risk is relatively big for enterprises which have greater financial risk and poor management. On the other hand, it shows that it is not enough to identify credit default enterprise, just based on quantitative analysis. We should make a multi- 
dimensional analysis, combining quantitative analysis with qualitative analysis. Otherwise, even a small error may result in great losses.

\section{Acknowledgment}

Project Source: Chongqing Municipal Higher Education Reform Project, Project No.112098

\section{References}

[1] W.Zhang, On the measurement and control of Chinese real estate credit risk. Jiangxi University of Finance and Economics. unpublished Ph.D. thesis, 2009.

[2] Y.Qin, Assessment on the internal control system of commercial bank credit risk based on fuzzy analysis. Shandong University unpublished Ph.D. thesis, 2008.

[3] H.Dan, On the credit risk management of state-owned commercial banks. Vol.1. Journal of Wuhan University (Social Science Edition), 2003, p.56.

[4] F.Jiang, Study on the comprehensive credit risk of modern commercial banks. Vol.5. Systematic Engineering, 2003, p.21.

[5] Michael K.Ong,Credit Rating Methodologies,Rational and Default Risk[M].Risk Books,2002. 